\title{
Prognostic value of rising mean platelet volume during hospitalization in patients with ST-segment elevation myocardial infarction treated with primary percutaneous coronary intervention
}

\author{
Eyup Avci ${ }^{1} \mathbb{D}$, Tuncay Kiris ${ }^{2 *}$, Aykan Çelik² ${ }^{2}$ Eser Variş ${ }^{3}$, Fatma Kayaalti Esin ${ }^{2}$, Diyar Köprülü ${ }^{4}$ and Hasan Kadi ${ }^{1}$
}

\begin{abstract}
Background: The prognostic significance of changes in mean platelet volume (MPV) during hospitalization in ST segment elevation myocardial infarction (STEMI) patients underwent primary percutaneous coronary intervention (pPCl) has not been previously evaluated. The aim of this study was to determine the association of in-hospital changes in MPV and mortality in these patients.

Methods: Four hundred eighty consecutive STEMI patients were enrolled in this retrospective study. The patients were grouped as survivors $(n=370)$ or non-survivors $(n=110)$. MPV at admission, and at $48-72 \mathrm{~h}$ was evaluated. Change in MPV (MPV at 48-72 $\mathrm{h}$ minus MPV on admission) was defined as $\triangle \mathrm{MPV}$.

Results: At follow-up, long-term mortality was $23 \%$. The non-survivors had a high $\triangle M P V$ than survivors $(0.37(-0.1-0.89)$ vs $0.79(0.30-1.40) \mathrm{fL}, p<0.001)$. A high $\triangle \mathrm{MPV}$ was an independent predictor of all cause mortality ((HR: 1.301 [1.070-1.582], $p=0.008)$. Morever, for long-term mortality, the AUC of a multivariable model that included age, LVEF, Killip class, and history of stroke/TIA was 0.781 (95\% Cl:0.731-0.832, $p<0.001$ ). When $\Delta$ MPV was added to a multivariable model, the AUC was 0.800 (95\% Cl: $0.750-0.848, z=2.256$, difference $p=0.0241$, Fig. 1). Also, the addition of $\triangle M P V$ to a multivariable model was associated with a significant net reclassification improvement estimated at 24.5\% ( $p=0.027)$ and an integrated discrimination improvement of $0.014(p=0.0198)$.
\end{abstract}

Conclusions: Rising MPV during hospitalization in STEMI patients treated with PPCI was associated with long-term mortality.

Keywords: Mean platelet volume, ST segment elevation myocardial infarction, Mortality

\section{Introduction}

Platelets (PLT) play an important role in in both initiation and progression of acute coronary syndromes (ACS) $[1,2]$. Previous studies have shown that platelets had pro-inflammatory activity independently of their actions of haemostasis and vascular thrombosis [3-5]. Mean platelet volume (MPV) is an indicator of platelet activation [6]. Large PLTs are more active and have

\footnotetext{
* Correspondence: drtkiris@hotmail.com

${ }^{2}$ Department of Cardiology, Ataturk Training and Research Hospital, Izmir Katip Celebi University, Basın Sitesi, 35360 Izmir, Turkey

Full list of author information is available at the end of the article
}

higher thrombotic potential compared with small PLTs. They are also more intense, and they have higher thromboxane A2 levels, and more glycoprotein Ib and IIb/IIIa receptors. Thus enabling PLT to aggregate more quickly with collagen more than the small PLTs [7].

In the recent years, numerous studies have been shown that the increased MPV at admission was associated with long-term mortality in patients with ACS [8-10]. Morever, an in-hospital increase in MPV after admission was found to be predictor of mortality in both non-ST segment elevation myocardial infarction and critical patients [11, 12]. There is no data about the association of in-hospital MPV

(c) The Author(s). 2018 Open Access This article is distributed under the terms of the Creative Commons Attribution 4.0 International License (http://creativecommons.org/licenses/by/4.0/), which permits unrestricted use, distribution, and reproduction in any medium, provided you give appropriate credit to the original author(s) and the source, provide a link to the Creative Commons license, and indicate if changes were made. The Creative Commons Public Domain Dedication waiver (http://creativecommons.org/publicdomain/zero/1.0/) applies to the data made available in this article, unless otherwise stated. 
change with mortality in patients with ST-elevation myocardial infarction (STEMI) treated with primary percutaneous coronary intervention (PCI).

The aim of the present study was to investigate the relationship of an in-hospital increase in MPV with long term mortality in STEM patient underwent primary PCI.

\section{Methods}

\section{Study population}

We enrolled 514 STEMI patients who were undergoing primary PCI between January 2008 and June 2015. The patients with malignancy or infectious disease or autoimmune disease or hematologic disease and patients with incompleted data were excluded from this study. The final analysis included 480 patients. Permission of study was obtained by a local ethics committee. STEMI diagnosis was established as typical angina pain lasting $>30 \mathrm{~min}$, with increase in levels of cardiac enzymes (troponin I levels) and electrocardiographic evidence of elevation of the ST segment of $>1 \mathrm{~mm}$ in two or more consecutive leads or the presence of new left bundle branch block (LBBB) [13]. We defined hypertension (HT) as the previous use of antihypertensive medication, systolic pressure $>140 \mathrm{mmHg}$ or diastolic pressure $>90 \mathrm{mmHg}$ and Diabetes mellitus as the use of insulin or antidiabetic agents or a fasting glucose level $>126 \mathrm{mg} / \mathrm{dL}$. Hypercholesterolemia was diagnosed as total cholesterol of $\geq 200 \mathrm{mg} / \mathrm{dL}$. Smoking was defined as a current smoker or not. This study complied with the Declaration of Helsinki.

We defined total mortality as death due to any cause at follow-up and considered as the primary end point. Morever, repeat revascularization, heart failure admission, and stroke/transient ischemic attack (TIA), and 30-day mortality were also evaluated. We obtained follow-up data from the hospital records, patients, and their relatives.

\section{Procedures}

All patients were treated according to the current guidelines.13 Primary PCI was performed using standard techniques via the transfemoral approach by 2 -experienced interventional cardiologists. The treatment strategies for each patient were left to the discretion of interventional cardiologists. We obtained angiographic data from the cardiac catheterization laboratory records. The infarct-related artery (IRA) was evaluated based on the thrombolysis in myocardial infarction (TIMI) classification. We defined invasive success in acute phase as reduction to $<\% 20$ in IRA obstruction and stenosis with TIMI-3 flow immediately after primary PCI. After angioplasty, all patients were transferred to intensive care unit. Dual antiplatelet therapy, beta-blockers, angiotensin-converting enzyme inhibitors
(ACE-I), angiotensin receptor-blocker (ARB), and statins were administered according to current guidelines [13].

The left ventricle ejection fraction (LVEF) was calculated after measuring the end-diastolic and end-systolic left ventricle (LV) volumes in the apical four-chamber and two-chamber views using the modified Simpson's method.

Blood sampling and hematological and biochemical analyses Peripheral blood was obtained for MPV analysis at admission prior to administration of antiplatelet drugs and 48-72 h after admission. Blood samples were collected into standardized tubes containing dipotassium ethylenediaminetetraacetate powder as anticoagulant and stored at room temperature. All measurements were analyzed within $1 \mathrm{~h}$ after collection. Change in MPV was defined as $\triangle \mathrm{MPV}$ (MPV at $48-72 \mathrm{~h}$ minus MPV on admission). An extra blood was collected on admission for biochemical analysis. They were evaluated by standard methods.

\section{Statistical analysis}

Statistical analysis was made using SPSS software (version 16.0; SPSS Inc., Chicago, IL, USA). Variables with normal distribution were analyzed using Kolmogorov-Smirnov test and presented as mean \pm standart deviation, while those without normal distribution were presented as medians with a range. Categorical variables were presented as number and percentage. The comparisons between groups was carried out using the chi-square test for categorical variables and Student $t$ tests or Mann-Whitney $\mathrm{U}$ test for continuous variables. A multivariate cox regression analysis was carried out to evaluate whether $\triangle \mathrm{MPV}$ was an independent predictor of mortality. Factors with a $p$ value of $<0.1$ by univariate analysis were included in multivariate cox regression analysis. The predictive values of a multivariable model and a combination of $\triangle \mathrm{MPV}$ with a multivariable model were estimated by comparing the areas under the receivers operating characteristic (ROC) curve. DeLong's test was used to compare the AUC from each of models [14], which were analysed by use of NCSS 12 software programme. Morever, the increased discriminative value after the addition of $\triangle \mathrm{MPV}$ to a multivariable model was also estimated using the Net Reclassification Improvement (NRI) and Integrated Discrimination Improvement [15]. Differences were considered significant at the 2-sided $p<0.05$ level.

\section{Results}

\section{Baseline characteristics}

Baseline demographic, and clinical characteristics are shown in Table 1. Median follow-up time was 65.9 (41.9-80.4) months. The non-survivors were significantly older ( $68 \pm 13$ vs $58 \pm 11, p<0.001)$. The histories of diabetes mellitus, HT, stroke/TIA were more common in non-survivors compared with survivors (Table 1). The 
Table 1 Baseline characteristics of the study population

\begin{tabular}{|c|c|c|c|}
\hline Variable & Survivors $(n=370)$ & Non-survivors $(n=110)$ & $P$-value \\
\hline Age (year) & $58 \pm 11$ & $68 \pm 13$ & $<0.001$ \\
\hline Female $n(\%)$ & $80(22)$ & $37(34)$ & 0.010 \\
\hline Hypertension $n(\%)$ & $151(41)$ & $63(57)$ & 0.002 \\
\hline Diabetes mellitus $n(\%)$ & $78(21)$ & $37(34)$ & 0.007 \\
\hline Hyperlipidemia n (\%) & $76(21)$ & $24(22)$ & 0.772 \\
\hline Current smoking $n(\%)$ & $168(45)$ & $40(36)$ & 0.098 \\
\hline Previous CAD n (\%) & $64(17)$ & $27(25)$ & 0.089 \\
\hline Prior stroke/TIA n (\%) & $5(1)$ & $9(8)$ & $<0.001$ \\
\hline Killip class $\geq 2$ n (\%) & $21(6)$ & $20(18)$ & $<0.001$ \\
\hline Multi-vessel disease $n(\%)$ & $132(36)$ & $57(52)$ & 0.002 \\
\hline GP IIb/Illa inhibitors n (\%) & $107(29)$ & 37 (34) & 0.343 \\
\hline \multicolumn{4}{|l|}{ Medication at discharge } \\
\hline Beta-blocker n (\%) & $319(86)$ & $82(73)$ & 0.004 \\
\hline Statin $n(\%)$ & $312(84)$ & $85(77)$ & 0.086 \\
\hline ACE-I/ARB $n(\%)$ & $315(85)$ & $76(69)$ & $<0.001$ \\
\hline DAPT $n(\%)$ & 365 (99) & $107(97)$ & 0.322 \\
\hline Infarct related artery & & & 0.097 \\
\hline LAD $n(\%)$ & $170(46)$ & $50(46)$ & \\
\hline$C \times \cap(\%)$ & $57(15)$ & $8(7)$ & \\
\hline RCA $n(\%)$ & $129(35)$ & $49(45)$ & \\
\hline Others $n(\%)$ & $14(4)$ & $3(2)$ & \\
\hline \multicolumn{4}{|l|}{ Outcomes } \\
\hline 30-day death n (\%) & $0(0)$ & $19(17)$ & $<0.001$ \\
\hline Stroke $n(\%)$ & $7(2)$ & $5(5)$ & 0.118 \\
\hline HF admission $n(\%)$ & $7(2)$ & $15(14)$ & $<0.001$ \\
\hline Myocardial reinfarction $n(\%)$ & $30(8)$ & $8(7)$ & 0.776 \\
\hline TVR n (\%) & $45(12)$ & $11(10)$ & 0.535 \\
\hline
\end{tabular}

$H F$ heart failure, CAD coronary artery disease, TIA transient ischemic attack, $A C E-I$ angiotensin-converting enzyme inhibitors, ARB angiotensin receptor blocker, TVR; target vessel revascularization, DAPT dual antiplatelet therapy

frequency of Killip class $\geq 2$ and multi-vessel disease were higher in non-survivors than survivors. Compared with survivors there was a higher proportion of women in non-survivors. The rates of usage of ACE-I/ARB and beta-blockers after discharge were lower in the non-survivors than survivors.

\section{Laboratory parameters}

Laboratory variables are provided in Table 2. Serum creatinine level at admission was higher in the non-survivors. Compared with survivors, admission hemoglobin level was lower in the non-survivors. There was no significant difference between groups in terms of platelet counts both at admission and at $48-72 \mathrm{~h}$. MPV at $48-72 \mathrm{~h}$ was higher in non-survivors than survivors. Compared with survivors, non-survivors had a high $\triangle \mathrm{MPV}$ value $[0.79(0.30-1.40)$ vs $0.37(-0.1-0.89), p<0.001]$. Baseline MPV was similar between groups.
LVEF was lower in non-survivors than survivors $(41 \pm 10$ vs $45 \pm 9, p<0.001)$.

\section{Clinical outcomes and $\triangle M P V$}

Thirty-day mortality rate was $20 \%$ in the non-survivors (Table 1). The frequencies of TVR, stroke, and MI were comparable between groups. Non-survivors had a higher incidence of HF admission compared with survivors (14\% vs $2 \%, p<0.001)$.

$\triangle \mathrm{MPV}$ (HR: 1.301 [1.070-1.582], $p=0.008)$, Killip class $\geq 2$, LVEF, history of stroke/TIA and age were independent predictors of long-term mortality in multivariate analysis (Table 3).

The ROC curve analysis of $\triangle \mathrm{MPV}$ revealed an area under the curve (AUC) of 0.646 for the prediction of long-term mortality. (Fig. 1). Morever, for long-term mortality, the AUC of a multivariable model that included age, LVEF, Killip class, and history of stroke/TIA was 0.781 
Table 2 The laboratory findings of study population

\begin{tabular}{|c|c|c|c|}
\hline Variable & $\begin{array}{l}\text { Survivor } \\
(n=370)\end{array}$ & $\begin{array}{l}\text { Non-survivor } \\
(n=110)\end{array}$ & $P$ value \\
\hline Total cholesterol (mg/dl) & $181 \pm 43$ & $163 \pm 39$ & 0.001 \\
\hline $\mathrm{SCr}^{\mathrm{a}}$ adm $(\mathrm{mg} / \mathrm{dl})$ & $0.86(0.76-1.02)$ & $0.95(0.80-1.26)$ & 0.048 \\
\hline Hemoglobin (g/dl) & $14.0 \pm 1.2$ & $13.2 \pm 2.2$ & $<0.001$ \\
\hline WBC count $\left(10^{3} / \mathrm{mm}^{3}\right)$ & $12 \pm 4$ & $12 \pm 5$ & 0.781 \\
\hline Platelets adm $\left(10^{3} / \mathrm{mm}^{3}\right)$ & $273 \pm 78$ & $271 \pm 93$ & 0.846 \\
\hline Platelets $48-72 \mathrm{~h}\left(10^{3} / \mathrm{mm}^{3}\right)$ & $241 \pm 73$ & $235 \pm 90$ & 0.448 \\
\hline $\mathrm{MPV}_{\text {adm }}((f \mathrm{f})$ & $9.0 \pm 1.6$ & $9.0 \pm 1.3$ & 0.648 \\
\hline $\mathrm{MPV}_{48-72 \mathrm{~h}}(\mathrm{fL})$ & $9.4 \pm 1.6$ & $9.8 \pm 1.4$ & 0.035 \\
\hline$\triangle \mathrm{MPV}^{\mathrm{a}}(\mathrm{fL})$ & $0.37(-0.1-0.89)$ & $0.79(0.30-1.40)$ & $<0.001$ \\
\hline LVEF (\%) & $45 \pm 9$ & $41 \pm 10$ & $<0.001$ \\
\hline
\end{tabular}

Abbreviations: $L V E F$ left ventricular ejection fraction, $S C r$ serum creatinine at admission, MPV mean platelet volume, $\triangle M P V$ change in mean platelet volume, WBC; white blood cell

${ }^{a}$ Comparison was made using Mann-Whitney $U$ test at $P<0.05$, and these values were described by median with inter-quartile range (25th and 75th percentile)

(95\% CI:0.731-0.832, $p<0.001$ ). When $\triangle \mathrm{MPV}$ was added to a multivariable model, the AUC was 0.800 (95\% CI: $0.750-0.848, \mathrm{z}=2.256$, difference $p=0.0241$, Fig. 1). Also, the addition of $\triangle \mathrm{MPV}$ to a multivariable model was associated with a significant net reclassification improvement estimated at $24.5 \%(p=0.027)$ and an integrated discrimination improvement of $0.014(p=0.0198)$. Kaplan-Meier survival curves according to a cut-point of $\triangle \mathrm{MPV}(\geq 0.44 \mathrm{fL}$ and $<0.44 \mathrm{fL}$ ) are shown in Fig. 2. In the subgroup analysis which was carried out according to the this cut-point, 30 -day mortality ( $2 \%$ vs $6 \%, p=0.009$ ), long-term mortality ( $16 \%$ vs $30 \%, p<0.001)$, and heart failure admission ( $3 \%$ vs $7 \%, p=0.028)$ were higher in high $\triangle \mathrm{MPV}$ group compared with low $\triangle \mathrm{MPV}$ group. There was no significant difference between groups in terms of myocardial reinfarction ( $8 \%$ vs $8 \%, p=0.756$ ), stroke ( $3 \%$ vs $3 \%, p=0.998)$ and TVR ( $12 \%$ vs $12 \%, p=0.974)$.

\section{Discussion}

To the best of our knowledge, this is the first study to investigate the association of an in-hospital increase in MPV and long-term mortality in patients with STEMI who were treated with pPCI. In present study, we found that an increase in hospital in MPV at $48-72 \mathrm{~h}$ was associated with long-term mortality in these patients.

An increase in MPV at $72 \mathrm{~h}$ has been shown Grabovac et al. in STEMI patients [16]. The presence of large PLTs are an indicator of the increased platelet activation. These PLTs are functionally predominantly hyperactivated and have a high granule content including intracellular thromboxane A2, procoagulant surface proteins such as P-selectin and GPIIIa, which is an indicator of prothrombotic state. Also, aggregation in response to collagen or ADP, thromboxane release and membrane expression of P-selectin or GP1b, GPIIb/IIIa have increased in these PLTs [17-19]. There is a relationship between MPV and both proinflammatory and prothrombotic conditions where thrombopoietin and various inflammatory

Table 3 Univariate and multivariate cox proportional hazards analysis for all-cause mortality

\begin{tabular}{|c|c|c|c|c|}
\hline \multirow[t]{2}{*}{ Variables } & \multicolumn{2}{|l|}{ Univariate } & \multicolumn{2}{|l|}{ Multivariate } \\
\hline & $\mathrm{HR}(95 \% \mathrm{Cl})$ & $P$-value & $\mathrm{HR}(95 \% \mathrm{Cl})$ & $P$-value \\
\hline Age (year) & $1.062(1.045-1.080)$ & $<0.001$ & $1.049(1.030 .0010-1.069)$ & $<0.001$ \\
\hline Gender (Male) & $0.581(0.391-0.864)$ & 0.007 & & \\
\hline History of stroke/TIA & $4.263(2.149-8.457)$ & $<0.001$ & $2.398(1.148-5.009)$ & 0.020 \\
\hline History of DM & $1.690(1.138-2.510)$ & 0.009 & & \\
\hline History of CAD & 1.695 (1.162-2.473) & 0.053 & & \\
\hline History of HT & $1.538(0.995-2.377)$ & 0.006 & & \\
\hline IRA & $0.987(0.823-1.183)$ & 0.888 & & \\
\hline Multi-vessel disease & $2.001(1.372-2.915)$ & $<0.001$ & & \\
\hline Killip $\geq 2$ & 3.619 (2.228-5.180) & $<0.001$ & $2.791(1.597-4.876)$ & $<0.001$ \\
\hline LVEF (\%) & $0.957(0.938-0.977)$ & $<0.001$ & $0.966(0.945-0.989)$ & 0.003 \\
\hline Hemoglobin (g/dl) & $0.832(0.763-0.907)$ & $<0.001$ & & \\
\hline$\triangle M P V(f L)$ & $1.428(1.210-1.685)$ & $<0.001$ & $1.301(1.070-1.582)$ & 0.008 \\
\hline Serum creatinine (mg/dl) & $1.235(1.091-1.397)$ & 0.001 & & \\
\hline Statin usage at discharge & $0.413(0.275-0.619)$ & $<0.001$ & & \\
\hline Beta-blocker usage at discharge & $0.496(0.326-0.756)$ & 0.001 & & \\
\hline ACE/ARB usage at discharge & $0.239(0.118-0.484)$ & $<0.001$ & & \\
\hline
\end{tabular}

Abbreviations: $H R$ hazard ratio, $C l$ confidence interval, $T I A$ transient ischemic attack, DM diabetes mellitus, $L V E F$ Left ventricular ejection fraction, $H T$ hypertension, $C A D$ coronary artery disease, $\triangle M P V$, change in mean platelet volüme, $A C E$ angiotensin-converting enzyme, $A R B$ angiotensin receptor blockers, IRA: infarct related artery 


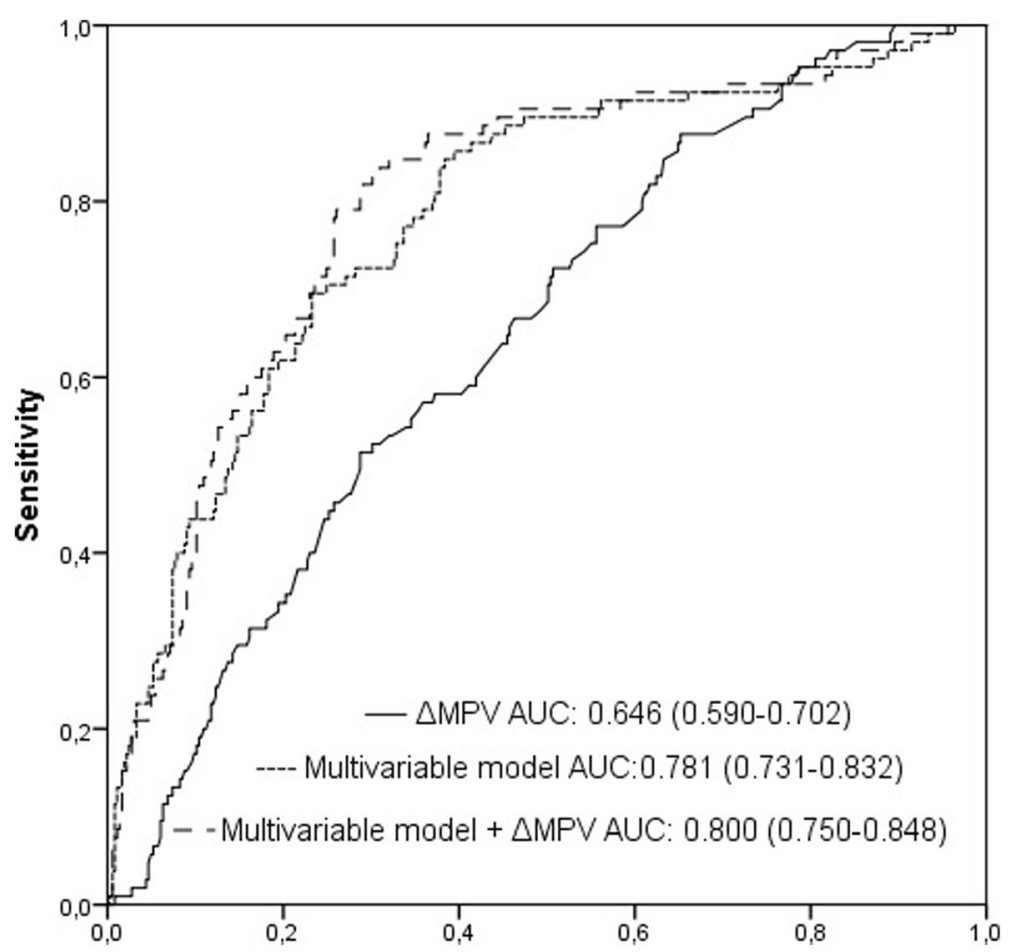

Fig. 1 Receiver operating characteristic (ROC) curves for the $\triangle M P V$, multivariable model, and multivariable model plus $\triangle M P V$ for predicting all-cause total mortality

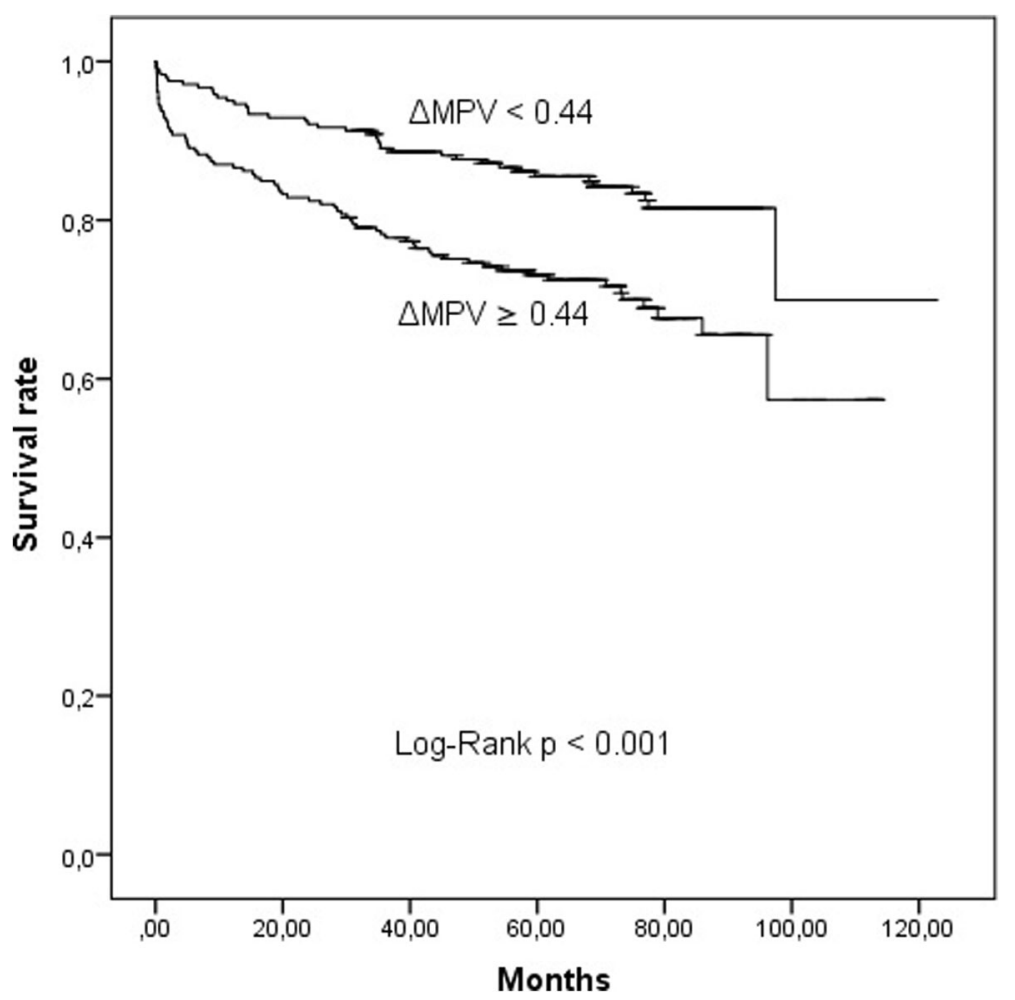

Fig. 2 Kaplan-Meier survival curves of all-cause mortality according to $\triangle M P V$ 
cytokines, such as interleukin (IL) 1, IL-3, and IL-6 and tumor necrosis factor (TNF) a, organize thrombosis. Furthermore, MPV has been shown to be a marker of inflammation in active inflammatory disease [20,21]. The contribution of PLT to inflammation, in which they perform this by binding to and activating to monocyte, was demonstrated in patients with MI $[22,23]$.

The mechanism for the enlarged circulating platelets at time after admission remains unclear. Newly generated PLTs arised from bone morrow megakaryocyte are usually bigger as size [18]. The time required for differentiation and maturation of megakaryocyte is about 4-5 days $[18,19]$. A period of $24 \mathrm{~h}$ is needed for de novo PLTs production and release of these from mature megakaryocytes. Therefore, it is less possible that early increase in MPV after MI is only the result of newly generated bigger PLTs from bone morrow. The human spleen serves as a reservoir for the circulating platelets (about one-third of body PLTs). Morever, MPV in PLTs from human spleen is approximally $20 \%$ greater than MPV in circulating PLTs. Thus, the spleen could be reservoir of large PLTs, and may be responsible for fast changes in number of circulating large PLTs under stress settings including intense exercise and stimulation by cytokines or catecholamines [24-27].

In a previous study, it has been shown that spleen thrombocyte release as a fast-acting mechanism increased in circulating MPV shortly after MI [28]. Spleen releasing monocytes and platelets to boost inflammation, has a key role in systemic response ischemic injury, and the another player of cardiosplenic axis is splenic PLTs [28]. In that study, they found that splenectomy broke these changes after MI in mice [28]. It is not clear what is responsible for the initiating of splenic PLTs release and activating of these after MI. The possible responsible mechanisms may be catecholamines and angiotensin II. Swirski et al. showed that these parameters increased in patients with acute MI [29]. Therefore, the elevated levels of angiotensin-II and catecholamin in acute MI setting may lead to splenic PLTs release.

PLTs have been shown to have an important role in inflammation [30]. The inflammatory properties of platelets are mediated by the interaction with large leukocytes [28]. The increased MPV as a reflection of both inflammation and pro-coagulant activity is associated with the risk of stent thrombosis, no-reflow via microthrombi or microvascular damage after PCI, myocardial reinfarction, large infarct size, post-MI heart failure, short and long term mortality in patients with acute MI [31-34].

Kiriş et al. showed there was a relationship between an increase in MPV at $24 \mathrm{~h}$ after admission and mortality in NSTEMI patients [11]. In that study, high $\triangle \mathrm{MPV}(>0.62 \mathrm{fL})$ patients had higher rate of both 30-day and long-term mortality as found in presented study. The difference between cut-points may be due to different clinical settings (i.e, STEMI vs NSTEMI) and applied treatment strategies. Another study published by Wang et al. demonstrated that serial changes in MPV was related to higher Killip class and no-reflow phenomenon after PCI in patients with STEMI treated with pPCI [35]. MPV at baseline, 30, 60, 90 days, and at 1, 2 and 3 years after PCI was evaluted in unselected coronary artery disease patients [36]. In that study, an increase in MPV over time was associated with long term mortality. In contrast to the their study, we investigated the association of in-hospital increase in MPV with mortality in STEMI patients who were undergoing pPCI. We found that an increase in-hospital MPV after admission was associated with mortality in these patients.

Medications including ACE-I/ARB, beta blockers, statins, and antiplatelet drugs may influence MPV [37, 38]. With regard to $\triangle \mathrm{MPV}$, we did not find any difference between patients receiving these drugs and those who did not. Morever, tirofiban usage had no effect on $\triangle \mathrm{MPV}$ in our study (data not shown). Further research is required to determine the impact of these treatments on $\triangle \mathrm{MPV}$.

A high $\triangle \mathrm{MPV}$ may be indicative of more thrombogenic and active platelets. Also, the presence of it may be a reflection of the increased thrombosis and inflammation. Thus, an increased PLTs size further contribute to the formation of thrombus. Morever, large size PLTs may lead to vasoconstriction and endotelial dysfunction. Therefore, the abovementioned associations may be possible underlying mechanisms of mortality in STEMI patients who were undergoing pPCI.

The present study has a few limitations. This is a retrospective study with a relatively small size, which precludes determining a definitive relationship between $\triangle \mathrm{MPV}$ and outcomes. The effect of different oral antiplatelts loading dose on MPV was not evaluated in the present study. Also, we could not investigate previous use of nonsteroidal anti-inflammatory drugs before PCI. The DM patients treated with incretin had a significantly lower rate of major cardiovascular events compared to those were not treated by this treatment $[39,40]$. As data regarding incretin usage was not present in many patients, its effect on mortality in present study could not be assesed. Moreover, we did not evaluated effect this agents on molecules involved in atherosclerotic plaque stability. Finally, possible selection bias may have impacted these results.

\section{Conclusion}

Rising MPV during hospitalization was associated with long-term mortality in STEMI patients treated with pPCI. We suggest that repeated MPV determinations throughout hospitalization may improve risk stratification in these patients. 


\section{Abbreviations}

ACS: Acute coronary syndrome; CAD: Coronary artery diseases; DM: Diabetes mellitus; HF: Heart failure; HT: Hypertension; IDI: Integrated discrimination improvement; LBBB: Leftbundle branch block; LVEF: Left ventricular ejection fraction; MPV: Mean platelet volume; NRI: Net reclassification improvement; PLT: Platelets; PPCl: Primary percutaneous coronary intervention; ROC: Receivers operating characteristic; sCr: Serum creatinine; STEMI: Stelevation myocardial infarction; TiA: Transient ischemic attack; TVR: Target vessel revascularization; WBC: White blood cell; $\triangle \mathrm{MPV}$ : Change in mean platelet volume

\section{Acknowledgements}

Not applicable.

\section{Funding}

The author(s) disclosed receipt of the following financial support for the research,authorship, and/or publication of this article: This research received no grant from anyfunding agency in the public, commercial, or not-for-profit sectors.

\section{Availabilityof data and materials}

Data are available from the corresponding author on reasonable request due to privacy or other restrictions.

\section{Authors' contributions}

TK, EA: conception and design of the work; EA, HD: acquisition, analysis, and interpretationof data; AC, EV, FKE: drafting the manuscript and revising it critically for important intellectual content; TK, DK and EA: final approval of the version to be published. All authors agreed to be accountable for all aspects of the work and in ensuring that questions related to the accuracy or integrity of any part of the work are appropriately investigated and resolved. All authors read and approved the final manuscript.

\section{Authors' information}

Eyup Avci takes responsibility for all aspects of the reliability and freedom from bias of the data presented and their discussed interpretation.

\section{Ethics approval and consent to participate}

The study was designed retrospectively. Balikesir University Ethics Committee waivered the need for informed consent regarding the retrospective data and approved this study.

\section{Consent for publication}

Not applicable.

\section{Competing interests}

The author(s) declared no potential conflicts of interest with respect to the research, authorship, and/or publication of this article.

\section{Publisher's Note}

Springer Nature remains neutral with regard to jurisdictional claims in published maps and institutional affiliations.

\section{Author details}

'Department of Cardiology, Medical School, Balikesir University, Balikesir, Turkey. ${ }^{2}$ Department of Cardiology, Ataturk Training and Research Hospital, Izmir Katip Celebi University, Basın Sitesi, 35360 Izmir, Turkey. ${ }^{3}$ Department of Cardiology, Dr. Burhan Nalbantoğlu State Hospital, Nicosia, Cyprus.

${ }^{4}$ Department of Cardiology, Ordu State Hospital, Ordu, Turkey.

Received: 29 June 2018 Accepted: 27 November 2018

Published online: 07 December 2018

\section{References}

1. Braunwald E, Antman EM, Beasley JW, et al. American College of Cardiology: American Heart Association. Committee on theManagement of patients with unstable angina. ACC/AHA 2002 guideline update for the management of patients with unstable angina and non-ST-segment elevation myocardial infarction-summary article: a report of the American College of Cardiology/American Heart Association task force on practice guidelines (committee on the Management of Patients with Unstable Angina). J Am Coll Cardiol. 2002;40(07):1366-74.
2. Fitzgerald DJ, Roy L, Catella F, Fitzgerald GA. Platelet activation in unstable coronary disease. N Engl J Med. 1986;315(16):983-9.

3. Zarbock A, Polanowska - Grabowska RK, Ley K. Platelet - neutrophil - interactions: linking hemostasis and inflammation. Blood Rev. 2007:21(2):99-111.

4. Gawaz M, Langer H, May AE. Platelets in inflammation and atherogenesis. J Clin Invest. 2005;115(12):3378-84.

5. Liu Y, et al. Novel role of platelets in mediating inflammatory responses and ventricular rupture or remodeling following myocardial infarction. Arterioscler Thromb Vasc Biol. 2011;31(4):834-41.

6. Pizzulli L, Yang A, Martin JF, Lüderitz B. Changes in platelet size and count in unstable angina compared to stable angina or noncardiac chest pain. Eur Heart J. 1998;19(01):80-4.

7. Martin JF, Penington DG. The relationship between the age and density of circulating 51-Cr labelled platelets in the sub-human primate. Thromb Res. 1983:30(02):157-64.

8. Sansanayudh N, Numthavaj P, Muntham D, et al. Prognostic effect of mean platelet volume in patients with coronary artery disease. A systematic review and meta-analysis. Thromb Haemost. 2015;1 14(06):1299-309.

9. Sansanayudh N, Anothaisintawee T, Muntham D, McEvoy M, Attia J, Thakkinstian A. Mean platelet volume and coronary artery disease: a systematic review and meta-analysis. Int J Cardiol. 2014:175(03):433-40.

10. Lai HM, Chen QJ, Yang YN, et al. Association of mean platelet volume with impaired myocardial reperfusion and short-term mortality in patients with STsegment elevation myocardial infarction undergoing primary percutaneous coronary intervention. Blood Coagul Fibrinolysis. 2016;27(01):5-12.

11. Kırış T, et al. The prognostic impact of in-hospital change in mean platelet volume in patients with non-ST-segment elevation myocardial infarction. Angiology. 2016;67(7):690-6.

12. Kim $\mathrm{CH}$, et al. An increase in mean platelet volume from baseline is associated with mortality in patients with severe sepsis or septic shock. PLoS One. 2015;10(3):e0119437.

13. Steg PG, James SK, Atar D, et al. ESC guidelines for the management of acute myocardial infarction in patients presenting with ST-segment elevation. Task force on the management of ST-segment elevation acute myocardial infarction of the European Society of Cardiology (ESC). Eur Heart J. 2012:33(20):2569-619.

14. DeLong ER, DeLong DM, Clarke-Pearson DL. Comparing the areas under two or more correlated receiver operating characteristic curves: a nonparametric approach. Biometrics. 1988;44(3):837-45.

15. Pencina MJ, D'Agostino RB Sr, Steyerberg EW. Extensions of net reclassification improvement calculations to measure usefulness of new biomarkers. Stat Med. 2011:30(1):11-21.

16. Sušilović Grabovac Z, Baković D, Lozo M, Pintarić I, Dujić Ž. Early changes in platelet size and number in patients with acute coronary syndrome. Int J Angiol. 2017;26(4):249-52.

17. Leader A, Pereg D, Lishner M. Are platelet volume indices of clinical use ? A multidisciplinary review. Ann Med. 2012:44(8):805-16.

18. Machlus KR, Italiano JE Jr. The incredible journey: from megakaryocyte development to platelet formation. J Cell Biol. 2013;201(6):785-96.

19. Thon JN, Italiano JE Jr. Does size matter in platelet production? Blood. 2012; 120(8):1552-61.

20. Gasparyan AY, Stavropoulos-Kalinoglou A, Toms TE, Douglas KM, Kitas GD. Association of mean platelet volume with hypertension in rheumatoid arthritis. Inflamm Allergy Drug Targets. 2010;9(1):45-50.

21. Makay B, Turkyilmaz Z, Unsal E. Mean platelet volume in children with familial Mediterranean fever. Clin Rheumatol. 2009;28(8):975-8.

22. Furman MI, Barnard MR, Krueger LA, et al. Circulating monocyte-platelet aggregates are an early marker of acute myocardial infarction. J Am Coll Cardiol. 2001;38(4):1002-6.

23. Sarma J, Laan CA, Alam S, Jha A, Fox KA, Dransfield I. Increased platelet binding to circulating monocytes in acute coronary syndromes. Circulation. 2002;105(18):2166-71.

24. Bakovic $D$, et al. The effects of low-dose epinephrine infusion on spleen size, central and hepatic circulation and circulating platelets. Clin Physiol Funct Imaging. 2013;33(1):30-7.

25. Bakovic $\mathrm{D}$, et al. Changes in platelet size and spleen volume in response to selective and non-selective beta-adrenoceptor blockade in hypertensive patients. Clin Exp Pharmacol Physiol. 2009;36(4):441-6.

26. Chamberlain KG, Tong M, Penington DG. Properties of the exchangeable splenic platelets released into the circulation during exercise-induced thrombocytosis. Am J Hematol. 1990;34(3):161-8. 
27. Wadenvik $\mathrm{H}$, Kutti J. The effect of an adrenaline infusion on the splenic blood flow and intrasplenic platelet kinetics. Br J Haematol. 1987;67(2):187-92.

28. Gao XM, et al. Splenic release of platelets contributes to increased circulating platelet size and inflammation after myocardial infarction. Clin Sci (Lond). 2016;130(13):1089-104.

29. Swirski FK, et al. Identification of splenic reservoir monocytes and their deployment to inflammatory sites. Science. 2009;325(5940):612-6.

30. Vorchheimer DA, Becker R. Platelets in atherothrombosis. Mayo Clin Proc. 2006;81(1):59-68.

31. Huczek Z, et al. Baseline platelet size is increased in patients with acute coronary syndromes developing early stent thrombosis and predicts future residual platelet reactivity. A case-control study. Thromb Res. 2010;125(5): 406-12.

32. Huczek Z, et al. Mean platelet volume on admission predicts impaired reperfusion and long-term mortality in acute myocardial infarction treated with primary percutaneous coronary intervention. J Am Coll Cardiol. 2005; 46(2):284-90.

33. Fabregat-Andrés $\mathrm{O}$, et al. Mean platelet volume is associated with infarct size and microvascular obstruction estimated by cardiac magnetic resonance in ST segment elevation myocardial infarction. Blood Coagul Fibrinolysis. 2013;24(4):424-7.

34. Tekbas $\mathrm{E}$, et al. Mean platelet volume in predicting short- and long-term morbidity and mortality in patients with or without ST-segment elevation myocardial infarction. Scand J Clin Lab Invest. 2011;71(7):613-9.

35. Wang XY, et al. Serial changes of mean platelet volume in relation to Killip class in patients with acute myocardial infarction and primary percutaneous coronary intervention. Thromb Res. 2015;135(4):652-8.

36. Shah B, Oberweis B, Tummala $L$, et al. Mean platelet volume and long-term mortality in patients undergoing percutaneous coronary intervention. Am J Cardiol. 2013;111(2):185-9.

37. Coban E, Afacan B. The effect of rosuvastatin treatment on the mean platelet volume in patients with uncontrolled primary dyslipidemia with hypolipidemic diet treatment. Platelets. 2008;19(2):111-4.

38. Jagroop IA, Mikhailidis DP. Angiotensin II can induce and potentiate shape change in human platelets: effect of losartan. J Hum Hypertens. 2000;14(9): $581-5$.

39. Marfella R, Sardu C, Balestrieri ML, Siniscalchi M, Minicucci F, Signoriello G, Calabrò P, Mauro C, Pieretti G, Coppola A, Nicoletti G, Rizzo MR, Paolisso G, Barbieri M. Effects of incretin treatment on cardiovascular outcomes in diabetic STEMlpatients with culprit obstructive and multivessel non obstructive-coronary-stenosis. Diabetol Metab Syndr. 2018;3(10):1.

40. Marfella R, Sardu C, Calabrò P, Siniscalchi M, Minicucci F, Signoriello G, Balestrieri ML, Mauro C, Rizzo MR, Paolisso G, Barbieri M. Non-ST-elevation myocardial infarction outcomes in patients with type 2 diabetes with nonobstructive coronary artery stenosis: Effects of incretin treatment. Diabetes Obes Metab. 2017. https://doi.org/10.1111/dom.13122 [Epub ahead of print].

Ready to submit your research? Choose BMC and benefit from:

- fast, convenient online submission

- thorough peer review by experienced researchers in your field

- rapid publication on acceptance

- support for research data, including large and complex data types

- gold Open Access which fosters wider collaboration and increased citations

- maximum visibility for your research: over $100 \mathrm{M}$ website views per year

At $\mathrm{BMC}$, research is always in progress.

Learn more biomedcentral.com/submissions 